\title{
In vitro antibiotic susceptibility testing of Brucella isolates from Egypt between 1999 and 2007 and evidence of probable rifampin resistance
}

\author{
Mohamed Abdel-Maksoud ${ }^{1 *}$, Brent House1 , Momtaz Wasfy', Bassem Abdel-Rahman', Guillermo Pimentel', \\ Gehan Roushdy ${ }^{2}$ and Erica Dueger ${ }^{1,3}$
}

\begin{abstract}
Background: Brucellosis poses a significant public health problem in Mediterranean countries, including Egypt. Treatment of this disease is often empirical due to limited information on the antibiotic susceptibility profiles of Brucella spp. in this region of the world. The aim of this study was to determine the antibiotic susceptibility profiles of Brucella blood isolates in Egypt, a country endemic for brucellosis.

Methods: Brucella spp. isolates were identified from the blood cultures of acute febrile illness (AFI) patients presenting to a network of infectious disease hospitals from 1999-2007. Minimum inhibitory concentrations were determined for tetracycline, gentamicin, doxycycline, trimethoprim-sulfamethoxazole, streptomycin, ceftriaxone, ciprofloxacin and rifampin using the E-test. Interpretations were made according to Clinical and Laboratory Standards Institute (CLSI) guidelines.

Results: A total of 355 Brucella spp. isolates were analyzed. All were susceptible to tetracycline, doxycycline, trimethoprim-sulfamethoxazole, streptomycin and ciprofloxacin; probable resistance to rifampin and ceftriaxone was observed among 277 (64\%) and 7 (2\%) of the isolates, respectively. Percentages of isolates showing probable resistance to rifampin were significantly lower before 2001 than in the following years (7\% vs. >81\%, p<0.01).

Conclusions: Despite the high burden of brucellosis in Egypt and frequent empirical treatment, isolates have remained susceptible to the majority of tested antibiotics. However, this is the first report of high rates of probable resistance to rifampin among Brucella isolates from Egypt. Patients should be closely monitored while following standard treatment regimens. Continued surveillance, drug susceptibility studies and updated CLSI interpretive criteria are needed to monitor and update antibiotic prescribing policies for brucellosis.
\end{abstract}

Keywords: Brucella, Brucellosis, MIC, Rifampin, Ceftriaxone, E-test, Egypt

\section{Introduction}

Brucellosis is endemic in many parts of the world, including Latin America, the Middle East, Africa, and Asia [1] and results in tremendous economic losses through reproductive failure in animals. Human disease is usually caused by $B$. melitensis $[2,3]$ and is contracted mainly through exposure to Brucella-contaminated milk and contagious organs from infected animals [4,5]. In developing countries brucellosis is commonly present

\footnotetext{
* Correspondence: Mohamed.abdelmaksoud.eg@med.navy.mil

'U.S. Naval Medical Research Unit No. 3, PSC 452, 5000, Cairo, Egypt Full list of author information is available at the end of the article
}

where small ruminants are kept. The disease was first reported in Egypt in 1939, and isolates characterized since then have belonged to B. melitensis biovar 3 [3]. In a previous surveillance study on acute febrile illness (AFI) patients in Egypt, the estimated annual incidence of brucellosis ranged from 64 to 70 per 100,000 population [6].

According to World Health Organization (WHO) guidelines, the recommended combination of treatment drugs for human brucellosis is doxycycline along with either rifampin or streptomycin [7], a recommendation that has been in place for more than a decade [8]. Although Brucella isolates are generally considered 
susceptible to these antibiotics, sporadic cases of antibiotic resistance and disease relapse have been reported $[9,10]$. However, routine antimicrobial susceptibility testing is generally not conducted for Brucella due to its fastidious growth requirements, risk of laboratoryacquired infections and need for biological safety level 2 or 3 precautions. The aim of this study was to take advantage of an unprecedented opportunity to test a repertoire of Brucella isolates $(\mathrm{n}=355)$ collected from Egypt over an eight year period to define the most common species and evaluate the minimum inhibitory concentrations (MICs) of eight commonly used antibiotics. Trends of bacterial resistance will be evaluated during the study period.

\section{Materials and methods}

Brucella isolates were obtained from blood culture aspecimens collected between 1999 and 2007 during sentinel site surveillance activities for AFI conducted in 13 infectious disease hospitals from four regions in Egypt: Alexandria, the Nile delta, Cairo and Upper Egypt. The protocol was approved by NAMRU-3 institutional review board and informed consents were available from all patients who enrolled into this study. Isolates were identified based on colony morphology, Gram staining, oxidase and catalase testing, production of urease, the requirement of $\mathrm{CO}_{2}$ for growth, $\mathrm{H}_{2} \mathrm{~S}$ production, sensitivity to dyes (e.g. basic fuchsin and thionin) and seroagglutination [11]. Confirmatory speciation testing was done using PCR [12].

Susceptibility to eight antibiotics - tetracycline, gentamicin, doxycycline, trimethoprim-sulfamethoxazole, streptomycin, ceftriaxone, ciprofloxacin and rifampin - was determined using the E-test (AB Biodisk, Solana, Sweden), which is reliable, reproducible, easily performed and produces similar results to those of conventional methods for Brucella [8]. Briefly, MuellerHinton agar plates supplemented with 5\% sheep blood were inoculated with bacterial suspensions calibrated to
0.5 McFarland standard turbidity and E-test strips were applied. The plates were placed in a $5 \% \mathrm{CO}_{2}$ incubator for 48 hours and the resulting growth was examined to determine the MIC for streptomycin, tetracycline, doxycycline and trimethoprim-sulfamethoxazole according to CLSI guidelines for potential bacterial agents of bioterrorism [13]. Because breakpoints for Brucella against the other antibiotics tested have not been officially established, guidelines for slow-growing bacteria (Haemophilus spp.) were employed as has been done elsewhere [8]. Trends of bacterial resistance over the study period were evaluated. The reference strains $H$. Influenza ATCC 10211 and S. pneumonia ATCC 49619 were used as controls.

\section{Results}

All Brucella isolates were identified as B. melitensis by biochemical testing and PCR and were shown to be susceptible to tetracycline $\left(\mathrm{MIC}_{90}=0.19 \mu \mathrm{g} / \mathrm{ml}\right)$, trimethoprim-sulfamethoxazole $\left(\mathrm{MIC}_{90}=0.19 \mu \mathrm{g} / \mathrm{ml}\right)$, doxycycline $\left(\mathrm{MIC}_{90}=0.25 \mu \mathrm{g} / \mathrm{ml}\right)$ and streptomycin $\left(\mathrm{MIC}_{90}=2 \mu \mathrm{g} / \mathrm{ml}\right)$. In addition, all strains were susceptible to ciprofloxacin $\left(\mathrm{MIC}_{90}=0.38 \mu \mathrm{g} / \mathrm{ml}\right)$ according to the criteria for slow-growing bacteria (Table 1 ). However, the MIC values for rifampin ranged from $0.25-4.0 \mu \mathrm{g} / \mathrm{ml}$, and according to CLSI breakpoints for slow-growing bacteria (Haemophilus spp.), reduced susceptibility (MIC $2-3 \mu \mathrm{g} / \mathrm{ml}$ ) in 158 isolates (45\%) and probable resistance (MICs $\geq 4 \mu \mathrm{g} / \mathrm{ml}$ ) in 69 isolates (19\%) were demonstrated. Only seven isolates (2\%) demonstrated probable resistance to ceftriaxone (Table 2).

Although the number of isolates collected from the same regions per year was variable, the MIC for rifampin showed an increase over time. For example, the percentage of isolates showing probable resistance to rifampin was significantly lower (7\%) in 85 isolates from 1999 and 2000 than in 270 isolates (81\%) from 2001-2009 $(\mathrm{p}<0.01)$ (Table 3).

Table 1 MIC ranges, MIC $_{50}$ and MIC $_{90}$ values of eight antibiotics against Brucella isolates

\begin{tabular}{|c|c|c|c|c|c|c|}
\hline \multirow[t]{2}{*}{ Antibiotics } & \multirow{2}{*}{$\begin{array}{l}\text { Range } \\
(\mu \mathrm{g} / \mathrm{ml})\end{array}$} & \multirow[t]{2}{*}{$\mathrm{MIC}_{50}$} & \multirow[t]{2}{*}{$\mathrm{MIC}_{90}$} & \multicolumn{3}{|c|}{ CLSI Breakpoints for Brucella ( $\mu \mathrm{g} / \mathrm{ml})$} \\
\hline & & & & $\mathrm{S}$ & I & $\mathbf{R}$ \\
\hline Trimethoprim-Sulfamethoxazole & $0.006-0.75$ & 0.047 & 0.19 & $\leq 2 / 38$ & - & - \\
\hline Tetracycline & $0.023-0.75$ & 0.125 & 0.19 & $\leq 1$ & - & - \\
\hline Doxycycline & $0.016-0.5$ & 0.125 & 0.25 & $\leq 1$ & - & - \\
\hline Ciprofloxacin & $0.125-0.75$ & 0.25 & 0.38 & $\leq 1^{a}$ & - & - \\
\hline Ceftriaxone & $0.064-4$ & 0.5 & 1 & $\leq 2^{a}$ & - & - \\
\hline Streptomycin & $0.125-3$ & 1.5 & 2 & $\leq 8$ & - & - \\
\hline Gentamicin & $0.094-3$ & 0.5 & 1 & Not defined & & \\
\hline Rifampin & $0.25-6$ & 2 & 4 & $\leq 1^{a}$ & $2^{a}$ & $\geq 4^{a}$ \\
\hline
\end{tabular}

${ }^{a}$ CLSI breakpoints for slow-growing bacteria (Haemophilus spp.). 
Table 2 Distribution of MICs values among Brucella isolates from AFI patients

\begin{tabular}{|c|c|c|c|c|c|c|c|c|}
\hline \multirow[t]{2}{*}{ MICs } & \multicolumn{8}{|c|}{ Antibiotics/No. of isolates } \\
\hline & TS & $\mathrm{TC}$ & $\mathrm{DC}$ & $\mathrm{Cl}$ & GM & TX & SM & $\mathbf{R I}$ \\
\hline 0.006 & 2 & & & & & & & \\
\hline 0.008 & 8 & & & & & & & \\
\hline 0.012 & 10 & & & & & & & \\
\hline 0.016 & 26 & & 1 & & & & & \\
\hline 0.023 & 40 & 3 & 1 & & & & & \\
\hline 0.032 & 48 & 7 & 5 & & & & & \\
\hline 0.047 & 62 & 24 & 19 & & & & & \\
\hline 0.064 & 37 & 66 & 49 & & & 3 & & \\
\hline 0.094 & 28 & 67 & 72 & & 1 & 2 & & \\
\hline 0.125 & 44 & 100 & 108 & 2 & 7 & 6 & 4 & \\
\hline 0.19 & 19 & 57 & 58 & 12 & 21 & 14 & 4 & \\
\hline 0.25 & 11 & 23 & 29 & 32 & 49 & 30 & 10 & 4 \\
\hline 0.38 & 13 & 6 & 10 & 22 & 47 & 69 & 10 & 2 \\
\hline 0.5 & 3 & 1 & 3 & 9 & 81 & 98 & 21 & 10 \\
\hline 0.75 & 4 & 1 & & 2 & 77 & 77 & 41 & 24 \\
\hline 1 & & & & & 47 & 41 & 61 & 37 \\
\hline 1.5 & & & & & 18 & 8 & 80 & 51 \\
\hline 2 & & & & & 5 & 6 & 89 & 79 \\
\hline 3 & & & & & 2 & & 35 & 79 \\
\hline 4 & & & & & & 1 & & 69 \\
\hline 8 & & & & & & & & \\
\hline Total & 355 & 355 & 355 & 79 & 355 & 355 & 355 & 355 \\
\hline
\end{tabular}

TS = trimethoprim-sulfamethoxazole, $\mathrm{TC}=$ tetracycline, $\mathrm{DC}=$ doxycycline. $\mathrm{Cl}=$ ciprofloxacin, $\mathrm{GM}=$ gentamicin, $\mathrm{TX}=$ ceftriaxone, $\mathrm{SM}=$ streptomycin $\mathrm{Rl}=$ rifampin

\section{Discussion}

Transmission of $B$. melitensis from small ruminants to humans has become a significant problem in Middle Eastern and Mediterranean countries [2,14]. Although some $B$. abortus has been diagnosed in Egypt [5,14], all Brucella spp. isolates identified in this study were B. melitensis, probably associated with transmission from small ruminants [3].

Screening 355 isolates against a panel of eight antibiotics by the E-test method showed that trimethoprimsulfamethoxazole had the lowest MIC values, in agreement with previous reports from Italy and Peru [2,15], but considerably lower than other previous studies carried out in Turkey [16,17]. Nevertheless, higher rates of trimethoprimsulfamethoxazole resistance have been reported in other countries, including Mexico [18] and Saudi Arabia [19].

Tetracycline was active in vitro against all isolates, which is consistent with previous reports $[8,20]$. Similarly, the related doxycycline, which is a major component of most therapeutic regimens against Brucella infection, showed relatively low MICs, although lower values have been reported elsewhere [16,17].
While ciprofloxacin testing showed a significantly high $\mathrm{MIC}_{90}$ value, the effectiveness of this drug against Brucella infection remains controversial. Both higher and lower MICs have been reported previously for this drug $[17,21,22]$.

All Brucella isolates were susceptible to streptomycin in agreement with previous studies from various countries $[8,18]$. For gentamicin, breakpoints have not been defined by CLSI, but the range of isolate MICs varied from $0.094-3 \mu \mathrm{g} / \mathrm{ml}$, which is relatively higher than other values reported previously $(0.064-1.5 \mu \mathrm{g} / \mathrm{ml})$ [8].

Rifampin demonstrated the highest $\mathrm{MIC}_{90}$ value, with $45 \%$ of the isolates showing reduced susceptibility and 19\% probable resistance, according to CLSI criteria for slow-growing bacteria (Table 2). To our knowledge, this is the first report of high rates of reduced susceptibility to rifampin among Brucella isolates from Egypt, suggesting the emergence of isolates with variable degrees of resistance to this drug (CLSI criteria for slow-growing bacteria). Only a few isolates (8-9\%) with reduced susceptibility to rifampin have been described before in Turkey [16,23], Kuwait [24] and Mexico [18]. In another study conducted in Peru, only one Brucella isolate demonstrated reduced susceptibility to rifampin $(1.0 \mu \mathrm{g} / \mathrm{ml})$ [15].

Despite the high burden of human and animal brucellosis in Egypt and frequent empirical treatment, isolates have remained susceptible to the majority of test antibiotics. Whether or not the high rates of probable resistance to rifampin among Brucella isolates from Egypt had an impact on the treatment of patients is not known. One report from Egypt [9] observed relapse in 59.3\% of the patients with osteoarticular brucellosis who were treated for 5 months or less with two drugs (rifampicin + doxycycline). By contrast relapse occurred in $7.9 \%$ of patients who were treated for more than 5 months. This report also noted that there was no relapse in patients who received 3 drugs (rifampicin + streptomycin +

Table 3 Percentages of Brucella isolates with reduced susceptibility to rifampin (MIC $\geq 2 \mu \mathrm{g} / \mathrm{ml}$ ) from 1999-2007

\begin{tabular}{lccc}
\hline Year & $\begin{array}{c}\text { Number of } \\
\text { isolates tested }\end{array}$ & $\begin{array}{c}\text { Number of isolates with } \\
\text { rifampin(MIC } \geq \mathbf{2} \mathbf{~} \mathbf{g} / \mathbf{m l}\end{array}$ & \% \\
\hline 1999 & 19 & 1 & 5 \\
\hline 2000 & 66 & 6 & 9 \\
\hline 2001 & 63 & 41 & 65 \\
\hline 2002 & 13 & 13 & 100 \\
\hline 2003 & 10 & 10 & 100 \\
\hline 2004 & 7 & 7 & 100 \\
\hline 2005 & 20 & 20 & 100 \\
\hline 2006 & 100 & 81 & 81 \\
\hline 2007 & 57 & 46 & 81 \\
\hline Total & $\mathbf{3 5 5}$ & $\mathbf{2 2 5}$ & $\mathbf{6 3}$ \\
\hline
\end{tabular}


doxycycline) in combination, although treatment with streptomycin for long periods has been associated with ototoxic or nephrotoxic manifestations [25].

\section{Conclusions}

Future antimicrobial surveillance studies are critical to monitor patients for relapse or treatment failure and developing specific assessment breakpoints for testing the susceptibility of Brucella strains to rifampin and other appropriate antibiotics in Egypt and other endemic parts of the world.

\section{Competing interests}

The authors declare that they have no competing interests.

\section{Authors' contribution}

MA-M developed the concept, processed the samples and participated in writing the manuscript. BH, MOW, GP, and ED developed the concept, analyzed the results, wrote and reviewed the manuscript. BA-R and GR processed the samples and helped in analyzing the results and writing the manuscript. All authors read and approved the final manuscript.

\section{Copyright assignment statement}

Authors are employees of the U.S. Government. This work was prepared as part of their official duties. Title 17 U.S.C. §105 provides that 'Copyright protection under this title is not available for any work of the United States Government.' Title 17 U.S.C. \$101 defines a U.S. Government work as a work prepared by a military service member or employee of the U.S. Government as part of that person's official duties

\section{Disclaimer}

The views expressed in this article are those of the authors and do not necessarily reflect the official policy or position of the U.S. Department of the Navy, the U.S. Department of Defense, the U.S. Government, or the Egyptian Ministry of Health and Population.

\section{Financial support}

This work was supported by a grant from the U. S. Agency for International Development (USAID) and the U.S. Department of Defense Global Emerging Infections Surveillance and Response System (DoD-GEIS) (work unit number E022).

\section{Author details}

${ }^{1}$ U.S. Naval Medical Research Unit No. 3, PSC 452, 5000, Cairo, Egypt. ${ }^{2}$ Central Public Health Laboratory, Cairo, Egypt. ${ }^{3}$ U.S. Centers for Disease Control and Prevention, Atlanta, GA, USA.

Received: 28 May 2012 Accepted: 15 July 2012

Published: 28 August 2012

\section{References}

1. Memish ZA, Balkhy HH: Brucellosis and international travel. J Travel Med 2004, 11:49-55.

2. Marianelli C, Graziani C, Santangelo C, Xibilia MT, Imbriani A, Amato R, Neri D, Cuccia M, Rinnone S, Di Marco V, Ciuchini F: Molecular epidemiological and antibiotic susceptibility characterization of Brucella isolates from humans in Sicily, Italy. J. Clin. Microbiol 2007, 45:2923-2928.

3. Samaha H, Al-Rowaily M, Khoudair RM, Ashour HM: Multicenter study of Brucellosis in Egypt. Emerg Infect Dis 2008, 14:1916-1918.

4. Afifi S, Earhart K, Azab MA, Youssef FG, El Sakka H, Wasfy M, Mansour H, El Oun S, Rakha M, Mahoney F: Hospital-based surveillance for acute febrile illness in Egypt: a focus on community-acquired blood stream infections. AmJTrop Med Hyg 2005, 73:392-399.

5. Refai MK: Brucellosis in animals and man in Egypt. Egypt J Vet Sci 2003, 37:1-31.

6. Jennings GJ, Hajjeh RA, Girgis FY, Fadeel MA, Maksoud MA, Wasfy MO, ElSayed N, Srikantiah P, Luby SP, Earhart K, Mahoney F: Brucellosis as a cause of acute febrile illness in Egypt. Trans R Soc Trop Med Hyg 2007, 101:707-713.

7. World Health Organization: Brucellosis in humans and animals. Treatment of brucellosis in humans. WHO/CDS/EPR 2006, 7:36-38.

8. Turkmani A, loannidis A, Christidiou A, Psaroulaki A, Loukaides F, Tselentis Y: In vitro susceptibility of Brucella melitensis isolates to eleven antibiotics. Annals Clin. Microbiol. Antimicrob 2006, 5:24-29.

9. El Miedany YM, El Gaafary M, Baddour M, Ahmed I: Human brucellosis: do we need to revise our therapeutic policy? I Rheumatol 2003, 30:2666-2672.

10. Garcia-Rodrigez JA, Munoz Belilidio JL, Fresnadillo MJ, Trujillano I: In vitro activities of new Macrolides and Rifepentine against Brucella spp. Antimcrob. Agents Chemother 1993, 37:911-913.

11. Murray PR, Baron EJ, Pfaller MA, Tenover FC, Yolken RH: Manual of clinical microbiology, 7th ed. American society for microbiology 1999, :625-631.

12. Bricker BJ, Halling SM: Differentiation of Brucella abortus bv. 1, 2, and 4, Brucella melitensis, Brucella ovis, and Brucella suis bv. 1 by PCR. $J$ Clin Microbiol 1994, 32:2660-2666

13. Clinical and Laboratory Standards Institute: Performance Standards for Antimicrobial Susceptibility Testing. In Twentieth informational Supplement, CLSI document M 100-S20. PA, USA: Wayne; 2010.

14. El-Olemy GM, Atta AA, Mahmoud WH, Hamzah EG: Brucellosis in man-II. Isolation of the causative organisms with special reference to blood picture and urine constituents. Dev Biol Stand 1984, 56:573-578

15. Maves RC, Castillo R, Guillen A, Espinosa B, Meza R, Espinoza N, Nunez G, Sanchez L, Chacaltana J, Cepeda D, Gonzalez S, Hall ER: Antimicrobial susceptibility of Brucella melitensis isolates in Peru. Antimicrob Agents Chemother 2011, 55:1279-1281.

16. Baykam N, Esener H, Ergonul O, Eren S, Celikbas AK, Dokuzoguz B: In vitro antimicrobial susceptibility of Brucella species. Intern J Antimicrob Agents 2004, 23:405-407.

17. Bodur H, Balaban N, Aksaray S, Yetener V, Akinci E, Coplan A, Erbay A: Biotypes and antimicrobial susceptibilities of Brucella isolates. Scand J Infect Dis 2003, 35:337-338.

18. Lopez-Merino A, Contreras-Rodriguez A, Migranas-Ortiz R, Orrantia-Gradin R, Hernandez-Oliva GM, Guttierrez-Rubio AT, Cardenosa O: Susceptibility of Mexican brucella isolates to moxifloxacin, ciprofloxacin and other antimicrobials used in the treatment of human brucellosis. Scand I Infect Dis 2004, 36:636-638.

19. Memish Z, Mah MW, Al Mahmoud S, Al Shaalan M, Khan MY: Brucella bacteraemia: clinical and laboratory observation in 160 patients. J Infect 2000s, 40:59-63.

20. Kose S, Kilic S, Ozbel Y: Identification of Brucella species isolated from proven Brucellosis Patient in Izmir Turkey. J. Basic Micobiol 2005, 45:323-327.

21. Tanyel E, Coban AY, Koruk ST, Simsek H, Hepsert S, Cirit OS, Tulek N: Actual antibiotic resistant pattern of Brucella melitensis in central Anatolia. Saudi Med J 2007, 28:1239-1242.

22. Trujillano-Martin I, Garcia-Sanchez E, Martinez IM, Fresnadillo MJ, GarciaSanchez JE, Garcia-Rodriguez JA: In vitro activities of six new fluoroquinolones against Brucella melitensis. Antimicrob Agents Chemother 1999, 43:194-195.

23. Aliskan H, Turunc T, Demiroglu YZ, Colakoglu S, Arslan H: Investigation of in vitro antibiotic susceptibility of Brucella melitensis. Mikrobiyol Bul 2008, 42:125-129.

24. Dimitrov TS, Panigrahi D, Emara M, Al-Nakkas A, Awni F, Passadilla R: Incidence of Bloodstream Infections in a Specialty Hospital in Kuwait: 8Years Experience. Med Princ Pract 2005, 14:417-421.

25. Ronland PS, Wright CG: Topical Aminoglycoside cochlear otoxicity. In Otoxicity, by Ronald \& Rutka (eds.), Chapter 12. Hamilton, Ontario: BC Decker Inc; 2004:114.

doi:10.1186/1476-0711-11-24

Cite this article as: Abdel-Maksoud et al:: In vitro antibiotic susceptibility testing of Brucella isolates from Egypt between 1999 and 2007 and evidence of probable rifampin resistance. Annals of Clinical Microbiology and Antimicrobials 2012 11:24. 